\title{
Estimation of Lesser Antilles Vertical Velocity Fields Using a GNSS-PPP Software Comparison
}

\author{
Pierre Sakic, Benjamin Männel, Markus Bradke, Valérie Ballu, \\ Jean-Bernard de Chabalier, and Arnaud Lemarchand
}

\begin{abstract}
Vertical land motion in insular areas is a crucial parameter to estimate the relative sealevel variations which impact coastal populations and activities. In subduction zones, it is also a relevant proxy to estimate the locking state of the plate interface. This motion can be measured using Global Navigation Satellite Systems (GNSS), such as the Global Positioning System (GPS). However, the influence of the processing software and the geodetic products (orbits and clock offsets) used for the solution remains barely considered for geophysics studies.

In this study, we process GNSS observations of Guadeloupe and Martinique network (Lesser Antilles). It consists of 40 stations over a period of 18 years for the oldest site. We provide an updated vertical velocity field determined with two different geodetic software, namely EPOS (Gendt et al, GFZ analysis center of IGS-Annual Report. IGS 1996 Annual Report, pp 169-181, 1998) and GINS (Marty et al, GINS: the CNES/GRGS GNSS scientific software. In: 3rd International colloquium scientific and fundamental aspects of the Galileo programme, ESA proceedings WPP326, vol 31, pp 8-10, 2011) using their Precise Point Positioning modes. We used the same input models and orbit and clock offset products to maintain a maximum of consistency, and then compared the obtained results to get an estimation of the time series accuracy and the software influence on the solutions. General consistency between the solutions is noted, but significant velocity differences exist (at the $\mathrm{mm} / \mathrm{yr}$ level) for some stations.
\end{abstract}

\section{Keywords}

Lesser Antilles · Guadeloupe · Martinique · GNSS · Vertical velocity field · Subsidence · Processing comparison $\cdot$ Time series analysis

P. Sakic $(\varangle) \cdot$ B. Männel $\cdot$ M. Bradke

GFZ German Research Centre for Geosciences, Helmholtz-Zentrum Potsdam, Potsdam, Germany

e-mail: pierre.sakic@gfz-potsdam.de

V. Ballu

Littoral Environnement et Sociétés, CNRS \& University of La Rochelle, La Rochelle, France

J.-B. de Chabalier · A. Lemarchand

Institut de Physique du Globe de Paris, Université de Paris, Paris,

France

\section{Introduction}

Nowadays, the Global Navigation Satellite Systems (GNSS) have become an indispensable tool to monitor the Earth crust motion. Nevertheless, their use in some part of the world remains challenging. It is the case of the Lesser Antilles Subduction Zone, at the convergence of the NordAmerican Plate under the Caribbean Plate. This subduction is singular on several aspects: it is one of the slowest in the world $(\sim 2 \mathrm{~cm} / \mathrm{yr})$, the lack of emerged lands prevents the determination of a complete deformation profile like it 
can be done in other areas. Moreover, the islands of the volcanic arc are located too far from the trench, prohibiting most often the detection of significant velocity gradients with respect to the stable plate. Because of these reasons, the locking state deduced from GNSS observations, and thus megathrust risk is uncertain. Symithe et al. (2015) estimated with GNSS observations all along the volcanic arc a low coupling rate but did not exclude a megathrust possibility either. Since the estimation of a horizontal deformation rate is a difficult task for this area, vertical motion observations can then become a proxy to help the assessment of a potential strain accumulation (e.g. Mouslopoulou et al. 2016). Moreover, island areas are also threatened by the sea level rise, and extra subsidence can be an aggravating factor (Ballu et al. 2011). For these two reasons, measuring vertical motion in the Lesser Antilles is crucial. Some vertical movement assessments in this area were performed in the past. Paleo-geodesy based on coral reef growth tends to show a subsidence trend in Martinique and Les Saintes Islands (south of Guadeloupe archipelago) (Weil-Accardo et al. 2016; Leclerc and Feuillet 2019). This subsidence is corroborated by GNSS observations for a few stations within the vertical velocity ULR6 solution (SantamaríaGómez et al. 2017). However, an uplift with decreasing rate for la Désirade Island (West of the Guadeloupe Archipelago) was measured (Léticée et al. 2019). Even though GNSS exploitation in this area is challenging, the islands are generally well instrumented, especially the two islands of Guadeloupe and Martinique.

Therefore, this study has a double objective, technical and scientific: on one hand, we estimate a denser vertical velocity field using a maximum of GNSS data in the area. On the other hand, we compare and quantify the differences between the results (coordinates and velocities inferred from the time series) obtained with two GNSS processing software using homogeneous inputs.

\section{Data}

We considered the GNSS observations provided by three different station networks, namely the IPGP, the IGN/SONEL, and the ORPHEON networks. Maps of these networks on the two islands are represented in Fig. 1. All three have been deployed for different purposes. The IPGP (Institut de Physique du Globe de Paris) network, maintained by the two local volcanological and seismological observatories has been deployed since the early 2000s (the first stations, HOUE and SOUF, were installed in 2000) for geodynamic purposes. Some stations are installed in the vicinity of the volcanic domes to monitor the volcanic activity and the others are deployed to observe potential subduction induced deformations. This network gathers nowadays 28 stations, 20 in Guadeloupe and 8 in Martinique. Due to the remote and/or extreme conditions for some sites, the network is heterogeneous regarding the time series completeness and the continuity in time of the equipment used. The IGN/SONEL (Institut national de l'information géographique et forestière/Système d'observation du niveau des eaux littorales) maintains 4 stations in the area ( 2 in Guadeloupe and 2 in Martinique) mainly for reference frame geodesy, with an application to sea level monitoring for the two stations PPTG and FFT2 (Wöppelmann et al. 2011; Santamaría-Gómez et al. 2017). These stations are installed in the vicinity of tide gauges to monitor their vertical motion. The first station of this network is ABMF and was installed in 2008. Finally, the ORPHEON network which consists in 8 stations ( 5 in Guadeloupe and 3 in Martinique) was installed in 2013/2014 for RTK surveying purposes, but the notable continuity of the time series without any hardware change make them suitable candidates for geophysics use. These stations are provided within the framework of RENAG (Réseau national GNSS permanent, e.g. Walpersdorf et al. 2018; Rabin et al. 2018). We processed the data from May 2000 (deployment of HOUE and SOUF) to end of August 2018 for the IPGP stations and end of November 2018 for the other networks. The timeline of the used observations is represented in Fig. 2.

\section{$3 \quad$ Processing}

The observation set described below was processed using two different GNSS processing software, namely EPOS (Gendt et al. 1998; Uhlemann et al. 2015) and GINS (Marty et al. 2011; Loyer et al. 2012), but using a similar strategy, equivalent models and identical product inputs. The underlying idea is to quantify the intrinsic differences due to different software. We used a Precise Point Positioning approach with float ambiguity resolution. A PPP processing is the most suitable one for this area because the reduced number of IGS reference stations prevents efficient differential processing. Moreover, those reference stations can be affected by the same tectonic processes as the geophysics stations. Thus, IGS stations in the area (namely ABMF and LMMF) are used here as "regular" stations. We considered only GPS observations since most of the stations recorded only this constellation during most of the period considered. The orbits and clock offset products have been generated beforehand by the GFZ Analysis Center in preparation of the IGS Repro3 campaign (Männel et al. 2020). These products are consistent with ITRF2014 (Altamimi et al. 2016). Regarding the models used, we kept a consistency between the two software configurations. The same antenna eccentricities are used for both processings based on station site logs. 
Fig. 1 Maps of the stations in Guadeloupe and Martinique Islands used in this study. The colors represent the three different networks: blue for IPGP, orange for IGN/SONEL, green for ORPHEON/RENAG. (a)

Guadeloupe Archipelago. (b) Martinique Island

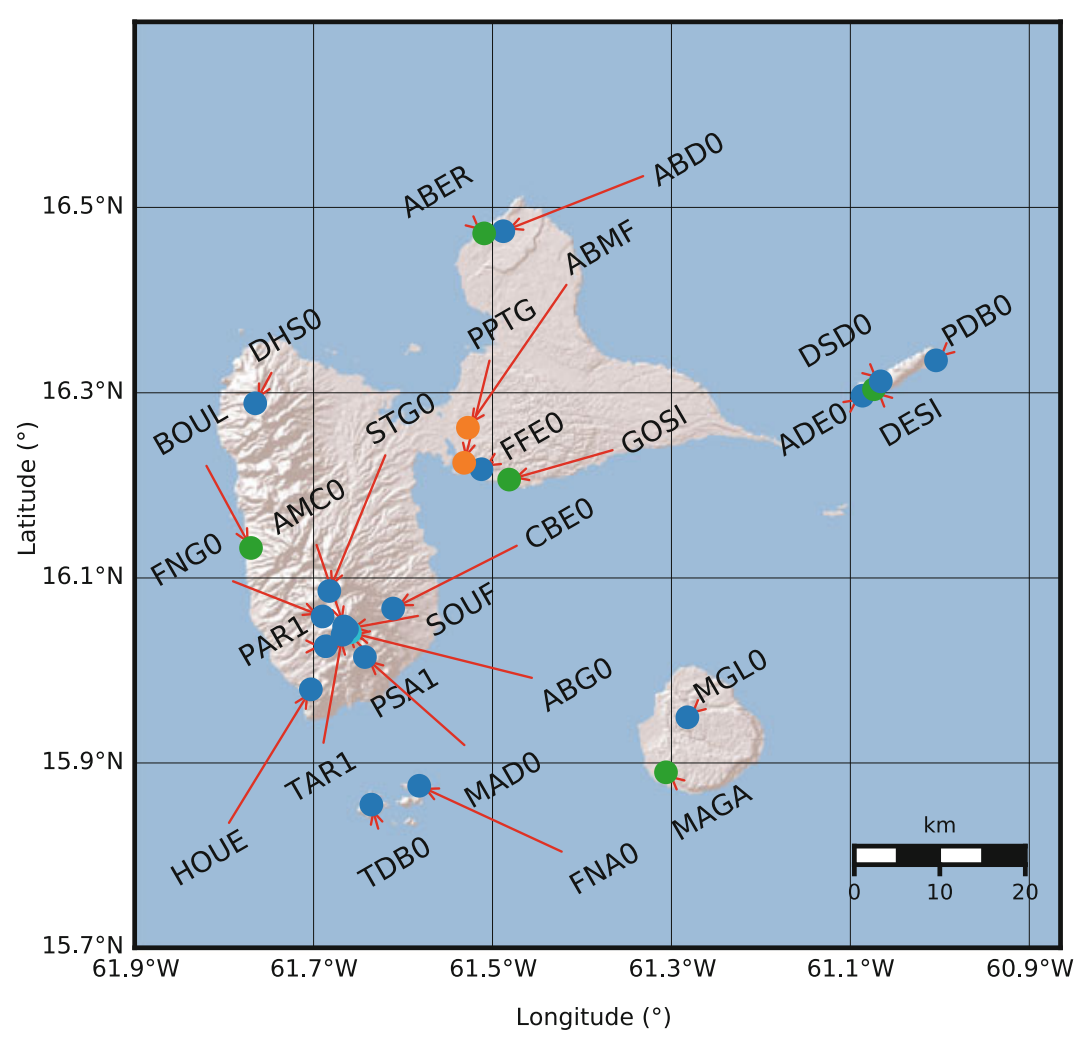

(a)

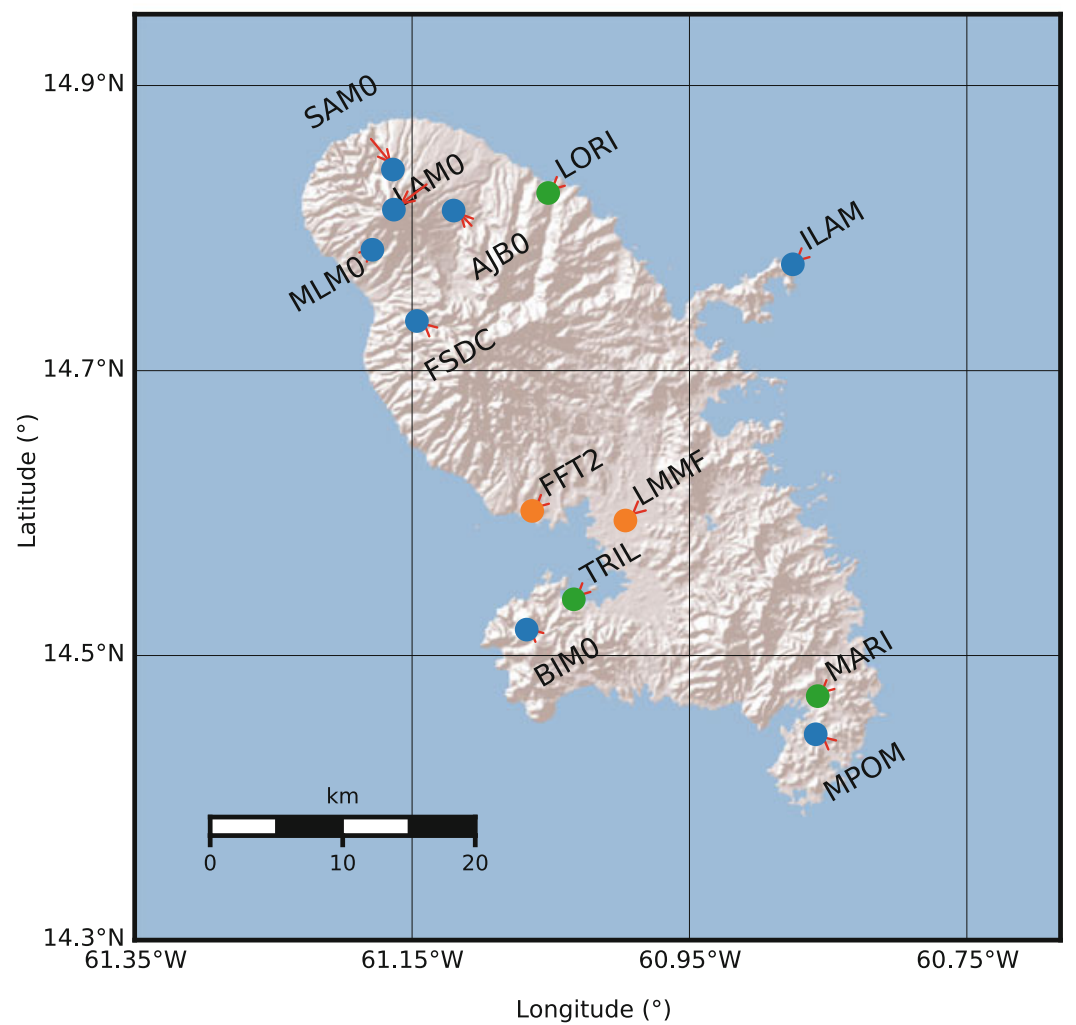

(b) 


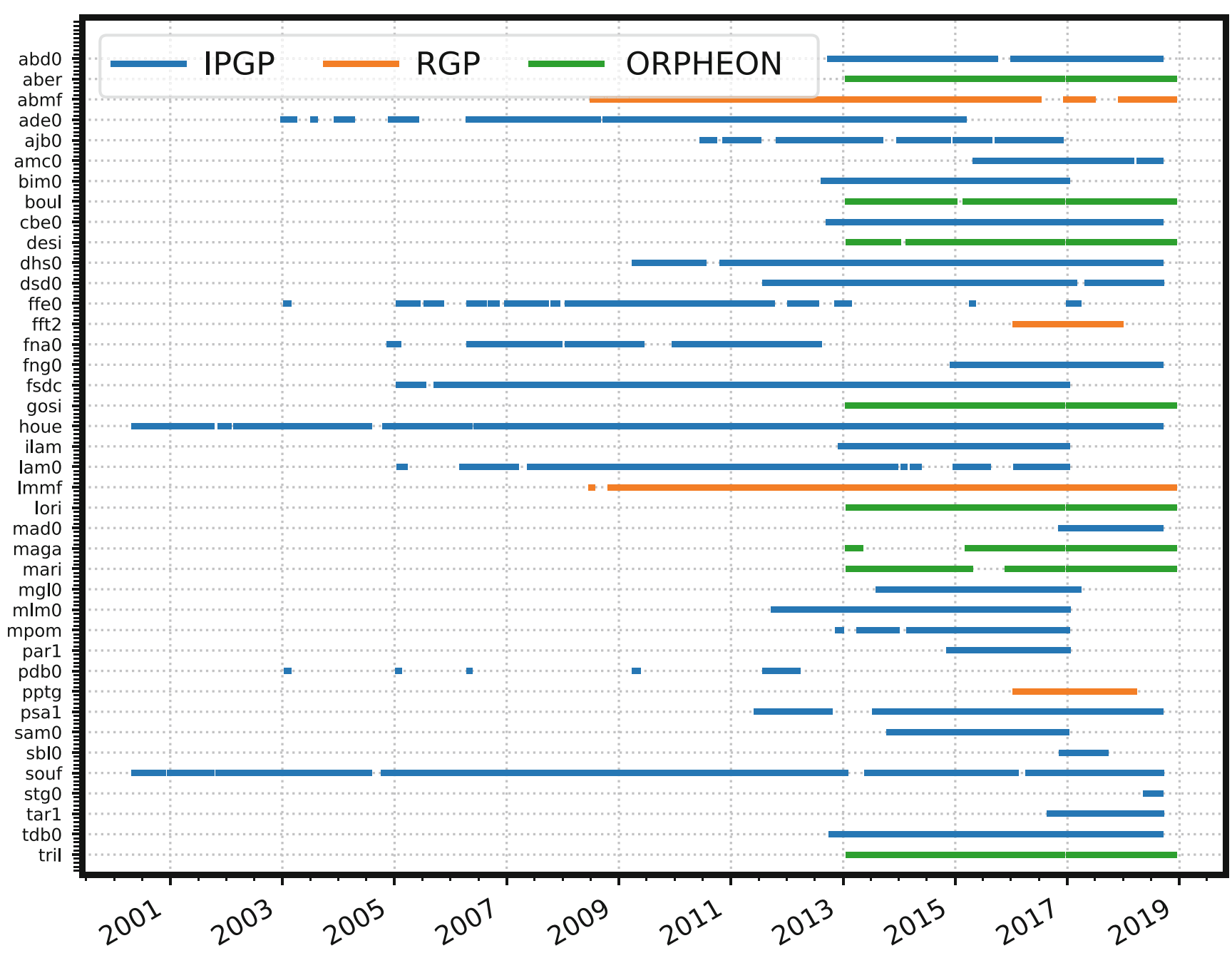

Fig. 2 Timeline of the daily observations processed from the three different networks available

Once the two daily coordinate sets are obtained, we select the intersection of both to get equivalent time series with the same daily coordinates. Indeed, some daily data were not properly computed by one or the other software. Stations STG0, SBL0 and PDB0 are completely excluded because of a lack of observations. For each time series, the corresponding velocities are determined using the trend estimation software HECTOR (Bos et al. 2013). We model the time series as combinations of a long term linear trend and an annual+semi-annual periodic signal, along with white and power-law noise. The term trend designates hereafter the linear component. The discontinuities introduced in the trend estimation are based on the material change site logs (an antenna change is systematically considered as a discontinuity) and on a supplementary visual detection (Sakic et al. 2019). The same discontinuities are applied for both equivalent EPOS and GINS solutions.

\section{$4 \quad$ Coordinate and Velocity Differences}

To quantify the impact of the processings, we compute the differences between the two coordinate sets for the three topocentric components and the planimetric distance (Euclidean norm of East and North components). These differences are represented as a histogram in Fig. 3 and the statistical indicators are given in Table 1. We remark that the mean difference for the three components is not centered on zero but is shifted by some millimeters. We also remark that the Up difference doesn't respect a Normal distribution, which reflects the fact that the Up component remains the hardest component to estimate with GNSS technique, mainly because this geometrical parameter is highly correlated to the clock offsets and tropospheric delay parameters. For the planimetric distance, the mean difference is $12.33 \mathrm{~mm}$ 


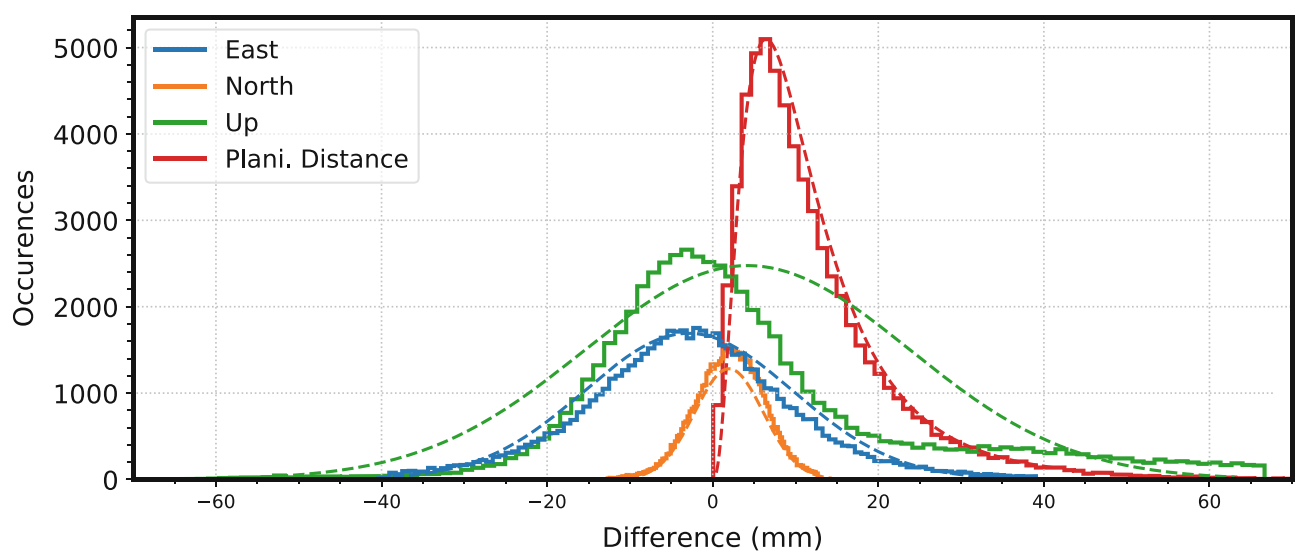

Fig. 3 Differences of the three topocentric coordinates and the planimetric distance for the common daily points of the two estimated solutions

Table 1 Mean, median and standard deviation in millimeters for the three topocentric coordinates and the planimetric distance for the common daily points of the two estimated solutions

\begin{tabular}{l|r|r|c}
\hline Component & Mean & Std. dev. & Median \\
\hline East & -2.89 & 12.69 & -2.92 \\
\hline North & 1.96 & 4.17 & 2.08 \\
\hline Up & 4.20 & 19.70 & 0.15 \\
\hline Plani. distance & 12.37 & 9.91 & 9.66 \\
\hline
\end{tabular}

but respects a Gamma distribution. Regarding the standard deviations $\sigma, \sigma_{\text {North }}$ is three times smaller than the $\sigma_{\text {East }}$, which can be explained by the better resolution of this component due to the general North-South trajectory of the satellites.

We compute also the differences between the two sets of estimated velocities obtained at the end of the processing, represented in Fig. 4. For the absolute differences (Fig. 4a), we observe notable differences at the $\mathrm{mm} / \mathrm{yr}$ level for the planimetric components, and for some stations a difference over $\pm 1 \mathrm{~mm} / \mathrm{yr}$ for the vertical component. Regarding the relative differences (Fig. $4 \mathrm{~b}$ ), we note differences on the order of $\pm 10 \%$ for the planimetric component, but for the vertical component, these differences can vary by more than a factor of two (stations over 100\%). Four stations have a negative relative variation, which means that they have an opposite velocity trend. Since the stations are sorted from the most complete set of data to the sparsest one, we observe no significative relation with the length of the time series.

\section{$5 \quad$ Vertical Velocity Results}

The vertical velocity values obtained for the two processings are given in Table 2 and represented in Fig. 5 for the Guadeloupe Archipelago, Fig. 6 for the specific area of the Soufrière Volcano, and Fig. 7 for the Martinique Island.
We note general subsidence for both islands. This tendency is consistent between the two solutions. For the Guadeloupe Archipelago, the subsidence is visible for most of the stations, nevertheless, a more complex behavior around the Soufrière area can be remarked, which might be related to local volcanic deformation but also the frequent hardware change due to the harsh conditions in the area (humidity, corrosion and frequent thunderstorms). On the Marie-Galante Island, South-West of the main island, the MGL0 station has a positive trend. Moreover, the four stations TDB0, ABD0 GOSI and DSD0, have opposite trend depending on the solution. For GOSI and DSD0, the velocities estimated in both cases are very close to zero, which make this opposite trend not significant. For GOSI, the different estimated velocities are still close to each other (with overlapping formal sigmas) but a clear velocity tendency for this station is also non-significant. The case of TDB0 is remarkable, since the time series is long and almost complete but the difference between the two solutions is important $(4.6 \mathrm{~mm} / \mathrm{yr})$. A detailed view of the raw time series and the estimated tendencies are shown in Fig. 8. We observe that the different scatter for both time series lead to a completely different estimation of the trend (using the strategy we selected). Station DHSO has a lot of corrupted raw data, which lead to a reduced amount of usable observation and an overestimated vertical velocity of almost $-2 \mathrm{~cm} / \mathrm{yr}$ for one solution. A similar statement can be made for FFE0 station on the main island, where several gaps in the time series along with several hardware changes might explain the positive trend estimated.

The mean velocity rate measured for all stations on the archipelago, with the volcano area excluded, is $-1.60 \pm 1.54 \mathrm{~mm} / \mathrm{yr}(1 \sigma)$ using EPOS solution, and $-2.17 \pm 1.23 \mathrm{~mm} / \mathrm{yr}(1 \sigma)$ using GINS solution.

For the Martinique Island, the two solutions are also consistent and general subsidence is observed except for SAM0 station. The mean velocity rate measured is 


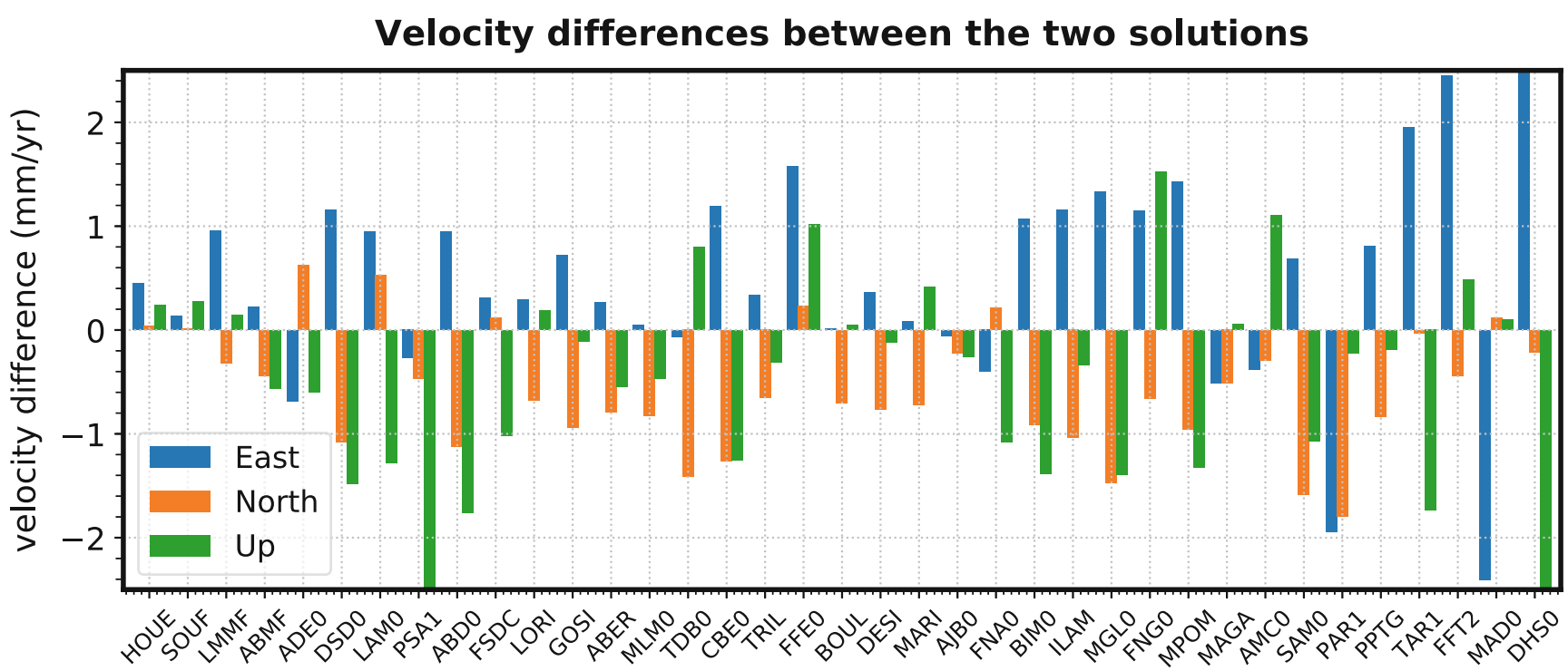

(a)

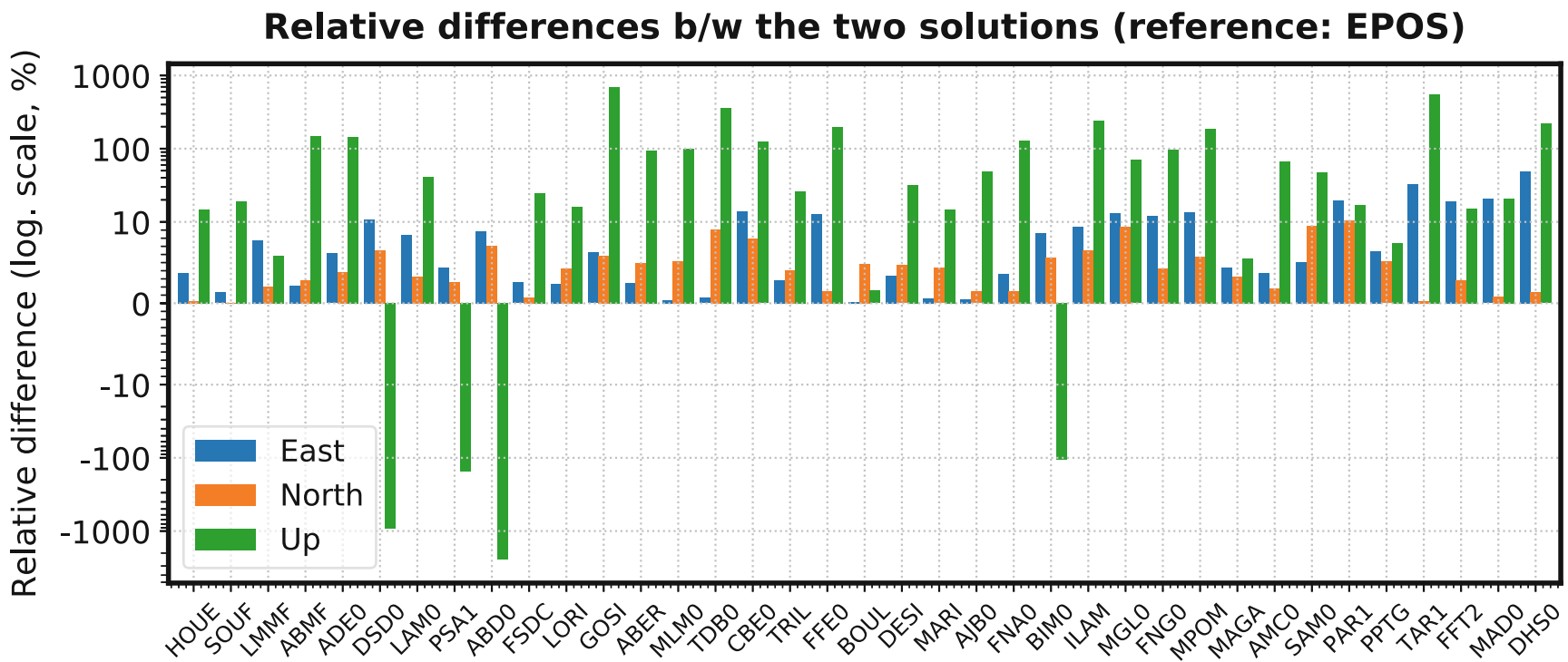

(b)

Fig. 4 Velocity difference for the three topocentric coordinates of the two estimated solutions. The stations are sorted from the most complete to the sparsest one. (a) Absolute velocity differences. (b) Relative velocity differences 
Table 2 Vertical velocities estimated for the Guadeloupe and Martinique network, for both EPOS and GINS solutions

\begin{tabular}{|c|c|c|c|c|c|c|c|c|c|c|c|c|c|}
\hline \multirow[b]{2}{*}{ Station } & \multirow[b]{2}{*}{ Purpose } & \multirow[b]{2}{*}{ Lat. } & \multirow[b]{2}{*}{ Long. } & \multirow[b]{2}{*}{ Start } & \multirow[b]{2}{*}{ End } & \multirow[b]{2}{*}{$\begin{array}{l}\text { Total } \\
\text { days }\end{array}$} & \multirow[b]{2}{*}{$\begin{array}{l}\text { Used } \\
\text { days }\end{array}$} & \multirow[b]{2}{*}{$\begin{array}{l}\text { Ratio } \\
(\%)\end{array}$} & \multirow[b]{2}{*}{$\begin{array}{l}\text { Discont. } \\
\text { (\#) }\end{array}$} & \multicolumn{2}{|c|}{$\begin{array}{l}\text { EPOS solution } \\
(\mathrm{mm} / \mathrm{yr})\end{array}$} & \multicolumn{2}{|c|}{$\begin{array}{l}\text { GINS solution } \\
(\mathrm{mm} / \mathrm{yr})\end{array}$} \\
\hline & & & & & & & & & & $V_{U p}$ & $\sigma V_{U p}$ & $V_{U p}$ & $\sigma V_{U p}$ \\
\hline $\mathrm{ABD} 0$ & $\mathrm{~T}$ & 16.47 & 298.51 & 2012-10-11 & 2018-08-30 & 2149 & 1843 & 85.76 & 1 & -0.81 & 0.99 & 0.38 & 0.70 \\
\hline ABER & $\mathrm{S}$ & 16.47 & 298.49 & 2013-01-30 & 2018-11-25 & 2125 & 1792 & 84.33 & 0 & -1.27 & 0.39 & -0.67 & 0.51 \\
\hline ABMF & $\mathrm{R}$ & 16.26 & 298.47 & $2008-07-15$ & 2018-11-25 & 3785 & 2926 & 77.31 & 2 & -0.84 & 0.40 & -0.39 & 0.42 \\
\hline ADE0 & $\mathrm{T}$ & 16.30 & 298.91 & 2003-01-31 & $2015-02-24$ & 4407 & 2504 & 56.82 & 1 & -0.96 & 0.62 & -0.37 & 0.58 \\
\hline AJB0 & $\mathrm{V}$ & 14.81 & 298.88 & 2010-06-29 & 2016-11-14 & 2330 & 1525 & 65.45 & 1 & -0.89 & 1.33 & -0.35 & 1.36 \\
\hline AMC0 & $\mathrm{V}$ & 16.05 & 298.33 & $2015-05-12$ & 2018-08-30 & 1206 & 1086 & 90.05 & 0 & -0.58 & 0.84 & -1.52 & 0.97 \\
\hline BIM0 & $\mathrm{T}$ & 14.52 & 298.93 & $2012-08-29$ & $2016-12-30$ & 1584 & 1399 & 88.32 & 0 & -0.17 & 0.59 & 1.12 & 0.71 \\
\hline BOUL & $\mathrm{S}$ & 16.13 & 298.23 & 2013-01-31 & 2018-11-25 & 2124 & 1680 & 79.10 & 0 & -3.40 & 0.93 & -3.46 & 0.95 \\
\hline CBE0 & $\mathrm{T}$ & 16.07 & 298.39 & $2012-09-30$ & 2018-08-30 & 2160 & 1740 & 80.56 & 0 & -2.17 & 1.34 & -0.93 & 1.45 \\
\hline DESI & $\mathrm{S}$ & 16.30 & 298.93 & 2013-02-04 & $2018-11-25$ & 2120 & 1657 & 78.16 & 0 & -0.41 & 0.42 & -0.36 & 0.51 \\
\hline DHS0 & $\mathrm{T}$ & 16.29 & 298.23 & 2009-04-16 & 2018-08-30 & 3423 & 336 & 9.82 & 2 & -18.20 & 2.41 & -8.29 & 3.80 \\
\hline DSD0 & $\mathrm{T}$ & 16.31 & 298.93 & 2011-08-11 & 2018-08-30 & 2576 & 2253 & 87.46 & 2 & -0.95 & 0.83 & 0.04 & 0.73 \\
\hline FFE0 & $\mathrm{T}$ & 16.22 & 298.49 & $2003-01-26$ & 2017-03-13 & 5160 & 1711 & 33.16 & 3 & 0.56 & 1.28 & 1.44 & 1.42 \\
\hline FFT2 & $\mathrm{R} / \mathrm{T}$ & 14.60 & 298.94 & 2016-01-27 & $2017-12-12$ & 685 & 642 & 93.72 & 0 & -2.84 & 1.28 & -3.32 & 1.56 \\
\hline FNA0 & $\mathrm{T}$ & 15.88 & 298.42 & 2004-11-26 & 2012-07-25 & 2798 & 1486 & 53.11 & 2 & -2.13 & 1.11 & -0.78 & 0.99 \\
\hline FNG0 & $\mathrm{T}$ & 16.06 & 298.31 & $2014-12-17$ & $2018-08-30$ & 1352 & 1173 & 86.76 & 1 & 0.09 & 1.91 & -1.29 & 1.44 \\
\hline FSDC & $\mathrm{T}$ & 14.73 & 298.85 & 2005-02-04 & $2016-12-30$ & 4347 & 1831 & 42.12 & 3 & -5.05 & 0.92 & -3.70 & 1.12 \\
\hline GOSI & $\mathrm{S}$ & 16.21 & 298.52 & 2013-01-30 & $2018-11-25$ & 2125 & 1796 & 84.52 & 0 & -0.16 & 0.37 & 0.03 & 0.44 \\
\hline HOUE & $\mathrm{T}$ & 15.98 & 298.30 & $2000-05-14$ & 2018-08-30 & 6682 & 4543 & 67.99 & 3 & -0.98 & 0.26 & -1.08 & 0.30 \\
\hline ILAM & $\mathrm{T}$ & 14.77 & 299.12 & 2012-12-19 & 2016-12-30 & 1472 & 1308 & 88.86 & 0 & -0.55 & 0.66 & -0.09 & 0.66 \\
\hline LAM0 & $\mathrm{V}$ & 14.81 & 298.84 & 2005-02-02 & 2016-12-30 & 4349 & 2045 & 47.02 & 6 & -4.60 & 1.02 & -3.27 & 0.80 \\
\hline LMMF & $\mathrm{R}$ & 14.59 & 299.00 & 2008-11-09 & 2018-11-25 & 3668 & 3247 & 88.52 & 2 & -2.40 & 0.46 & -2.41 & 0.41 \\
\hline LORI & $\mathrm{S}$ & 14.82 & 298.95 & 2013-02-06 & $2018-11-25$ & 2118 & 1797 & 84.84 & 0 & -1.02 & 0.35 & -1.17 & 0.39 \\
\hline MAD0 & $\mathrm{V}$ & 16.01 & 298.36 & 2016-11-22 & 2018-08-30 & 646 & 610 & 94.43 & 0 & 0.92 & 1.78 & 1.47 & 2.52 \\
\hline MAGA & $\mathrm{S}$ & 15.89 & 298.69 & 2013-02-02 & 2018-11-25 & 2122 & 1099 & 51.79 & 0 & -0.93 & 0.53 & -1.14 & 0.50 \\
\hline MARI & $\mathrm{T}$ & 14.47 & 299.14 & 2013-02-06 & 2018-11-25 & 2118 & 1568 & 74.03 & 0 & -2.43 & 0.40 & -2.73 & 0.45 \\
\hline MGL0 & $\mathrm{T}$ & 15.95 & 298.72 & 2013-08-20 & 2017-03-13 & 1301 & 1209 & 92.93 & 0 & 0.88 & 1.41 & 1.98 & 0.94 \\
\hline MLM0 & $\mathrm{V}$ & 14.78 & 298.82 & 2011-10-06 & 2016-12-30 & 1912 & 1776 & 92.89 & 0 & -0.85 & 0.93 & -0.44 & 1.24 \\
\hline MPOM & $\mathrm{T}$ & 14.44 & 299.14 & 2012-11-28 & 2016-12-30 & 1493 & 1170 & 78.37 & 0 & -1.91 & 0.76 & -0.86 & 0.70 \\
\hline PAR1 & $\mathrm{V}$ & 16.03 & 298.31 & 2014-11-21 & 2016-12-30 & 770 & 748 & 97.14 & 4 & 0.65 & 4.85 & 1.01 & 3.81 \\
\hline PPTG & $\mathrm{R} / \mathrm{T}$ & 16.22 & 298.47 & 2016-01-27 & 2018-03-09 & 772 & 718 & 93.01 & 0 & -2.79 & 1.12 & -2.83 & 1.06 \\
\hline PSA1 & $\mathrm{V}$ & 16.04 & 298.33 & 2011-06-16 & 2018-08-30 & 2632 & 1970 & 74.85 & 9 & -0.80 & 1.14 & 2.07 & 1.13 \\
\hline SAM0 & $\mathrm{V}$ & 14.84 & 298.84 & 2013-10-30 & 2016-12-21 & 1148 & 1055 & 91.90 & 0 & 1.28 & 1.17 & 2.31 & 1.22 \\
\hline SOUF & $\mathrm{V}$ & 16.04 & 298.34 & $2000-05-13$ & 2018-08-30 & 6683 & 4427 & 66.24 & 3 & -1.23 & 0.31 & -1.59 & 0.34 \\
\hline TAR1 & $\mathrm{V}$ & 16.04 & 298.33 & 2016-09-09 & 2018-08-30 & 720 & 659 & 91.53 & 10 & -2.95 & 2.31 & -1.80 & 2.97 \\
\hline TDB0 & $\mathrm{T}$ & 15.85 & 298.36 & 2012-10-18 & 2018-08-30 & 2142 & 1762 & 82.26 & 2 & 3.10 & 3.34 & -1.51 & 2.64 \\
\hline TRIL & $\mathrm{S}$ & 14.54 & 298.97 & 2013-02-05 & 2018-11-25 & 2119 & 1732 & 81.74 & 0 & -1.42 & 0.36 & -1.17 & 0.37 \\
\hline
\end{tabular}

The used days column refers to the common number of days correctly processed in both solutions, and used for the velocity estimation. The main purpose of each station in mentioned in the second column: we distinguish stations located in the vicinity of the volcano domes, and installed for volcanic deformation monitoring $(\mathrm{V})$, stations for tectonic deformation monitoring $(\mathrm{T})$, stations for reference frame definition and orbit determination (R), and stations for RTK surveying (S) 


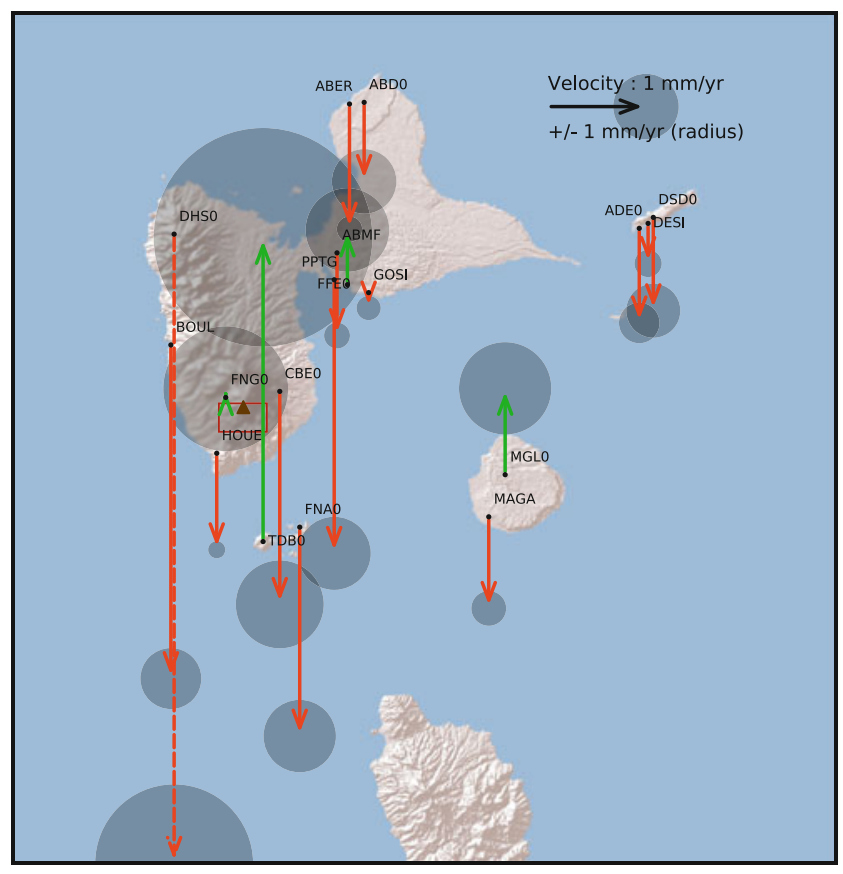

(a)

Fig. 5 Vertical velocity field obtained for the two solutions processed for stations located in Guadeloupe. A green arrow indicates an observed uplift and a red arrow an observed subsidence. The red rectangle

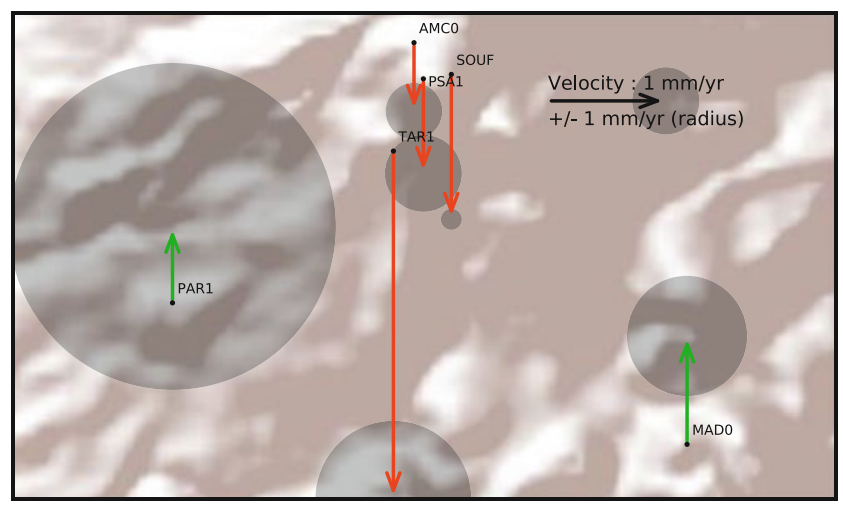

(a)

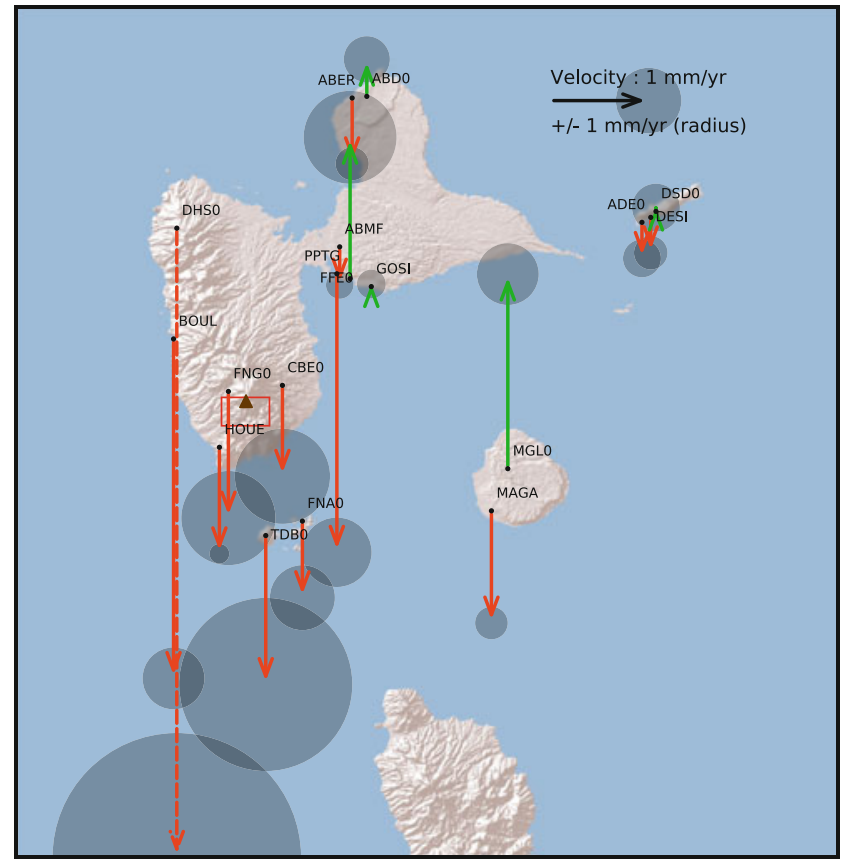

(b)

indicates the area around the Soufrière Volcano, presented in detail in Fig. 6. The volcano summit is represented with a brown triangle. Dashed arrows have been shortened to stay in the frame. (a) EPOS solution. (b) GINS solution

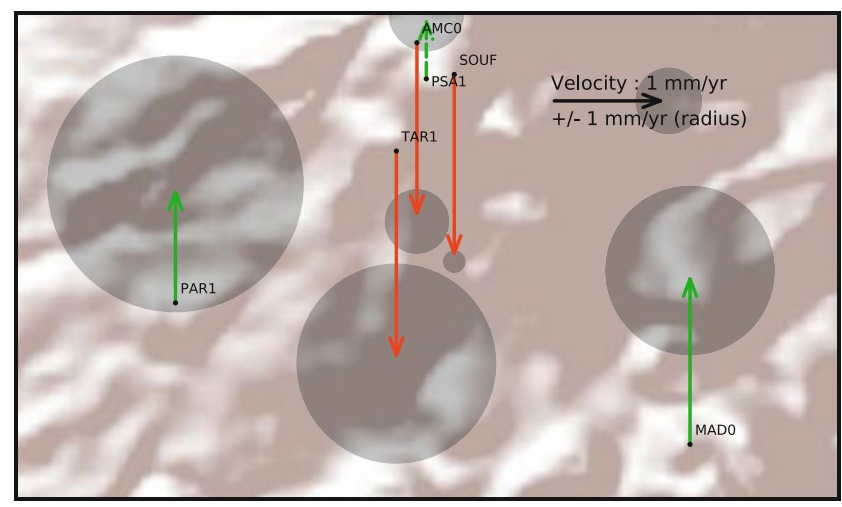

(b)

Fig. 6 Vertical velocity field obtained for the two solutions processed for stations located in the vicinity of the Soufrière Volcano (Basse-Terre, southern main Island of Guadeloupe). Dashed arrow has been shortened to stay in the frame. (a) EPOS solution. (b) GINS solution

$-1.80 \pm 1.36 \mathrm{~mm} / \mathrm{yr}(1 \sigma)$ using EPOS solution, and $-1.68 \pm 1.23 \mathrm{~mm} / \mathrm{yr}(1 \sigma)$ using GINS solution.

\section{Comparison with Existing Solutions}

To validate the consistency of our results, we compare the vertical velocities we determined with existing solutions for stations LMMF and ABMF (belonging to IGS network). We consider the velocities provided by
SONEL for ULR6a (Santamaría-Gómez et al. 2017), NGL14 (Blewitt et al. 2018), JPL14 (Heflin et al. 2019) and ITRF14 (Altamimi et al. 2016) solutions. Values are given in Table 3. For LMMF, the estimated velocities are consistent with each other $\left(\sigma_{V}=0.44 \mathrm{~mm}\right)$, while for $\mathrm{ABMF}$ we remark more important differences between each solution $\left(\sigma_{V}=0.79 \mathrm{~mm}\right)$, just like we have also differences between the values of this work's solutions. Nevertheless, the negative trend remains significant. 


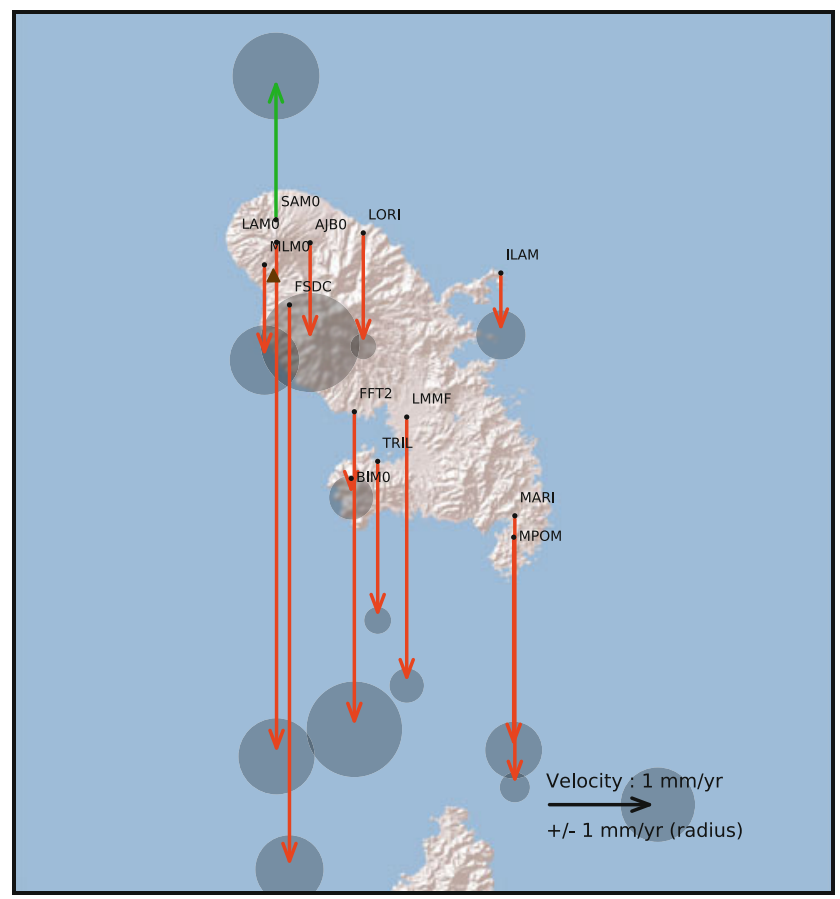

(a)

Fig. 7 Vertical velocity field obtained for the two solutions processed for stations located in Martinique. A green arrow indicates an observed uplift and a red arrow an observed subsidence. The volcano summit is

\section{Discussion}

Using two different solutions but based on the same geodetic products and homogeneous models, we obtain significant disparities in terms of coordinates difference repeatability, especially on the East and Up components with a standard deviation at the centimeter level. Regarding the estimated vertical velocities using the same set of points and the same discontinuities, the differences are also significant. This result tends to motivate investigation on velocity combination strategies between different processing centers, as suggested and tested by Ballu et al. (2019) for instance, where a joint least square modeling is developed to combine equivalent time series from different Analysis Centers. A combination based on a maximum likelihood estimation would be also an relevant method.

Nevertheless, for the studied area of the Guadeloupe and Martinique Islands, a negative velocity trend on the Up component is observed for most of the stations, which might suggest generalized subsidence of the area. This tendency is clear for the Martinique Island, but more complex trends for the Guadeloupe Archipelago can be observed, especially in the area around the Soufrière Volcano. This result can also be nuanced, since some stations have a positive trend, which might be due to local effects. A positive trend can also be

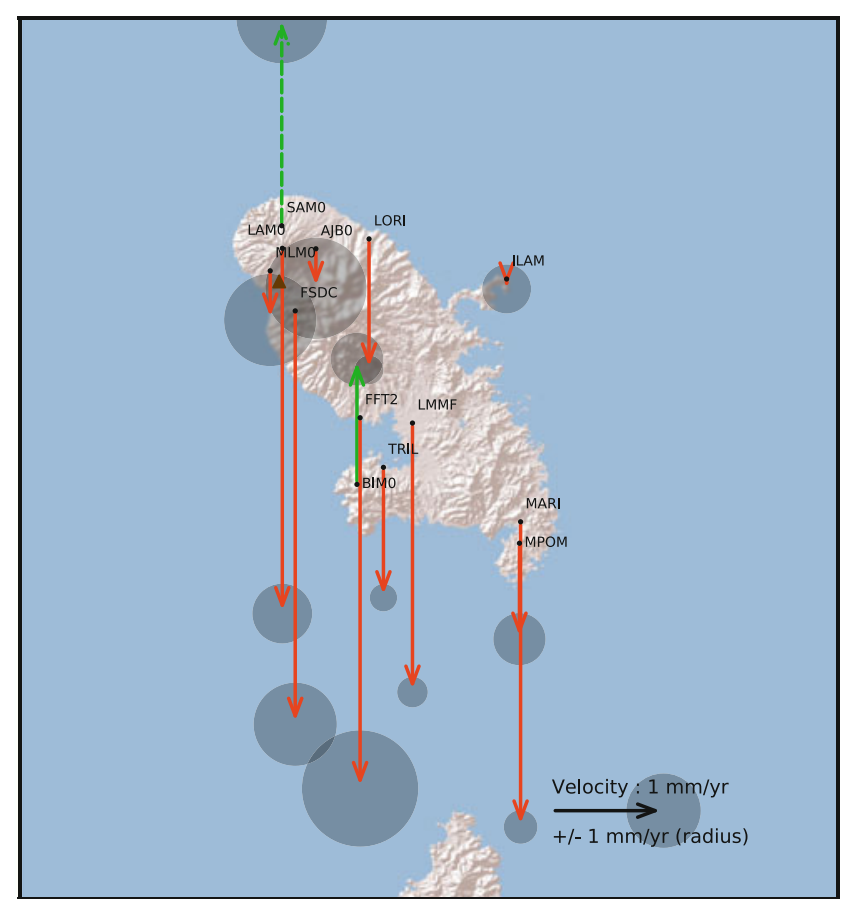

(b)

represented with a brown triangle. Dashed arrow has been shortened to stay in the frame. (a) EPOS solution. (b) GINS solution

due to an important number of discontinuities over the time series period, like the stations PAR1 (furthermore located inside the volcano area) and FFE0 (outside the volcano area). On another hand, a large number of discontinuities for the same station seem to lead also to an overestimated negative trend, like for instance the station LAM0, with a velocity estimated over $-3 \mathrm{~mm} / \mathrm{yr}$ for six discontinuities referenced. This statement reveals the necessity to maintain networks with a minimum of hardware discontinuities, i.e. by reducing the number of antenna changes. MGL0 station, located on the Marie-Galante Island, presents a singular behavior. It is the only station clearly uplifting, with a quasi-complete time-series of 3.5 years, without any visible discontinuity, while the other station on Marie-Galante (MAGA) presents a subsiding trend. Unfortunately, since this station belong to the commercial ORPHEON network, we have only a few metadata that prevent us to explain clearly this behavior.

We corroborate the paleo-geodesy studies carried out in the region. The coral reef records in Martinique (WeilAccardo et al. 2016) and Les Saintes (Leclerc and Feuillet 2019) indicate also a subsidence but with a smaller order of magnitude of few tenths of a millimeter per year, which can be explained by the difference in the observation time spans (only a few years for GNSS, $c a$. one century for the coral records). According to those studies, long term subsidence can have multiple origins: volcanic activity, crustal faulting, 


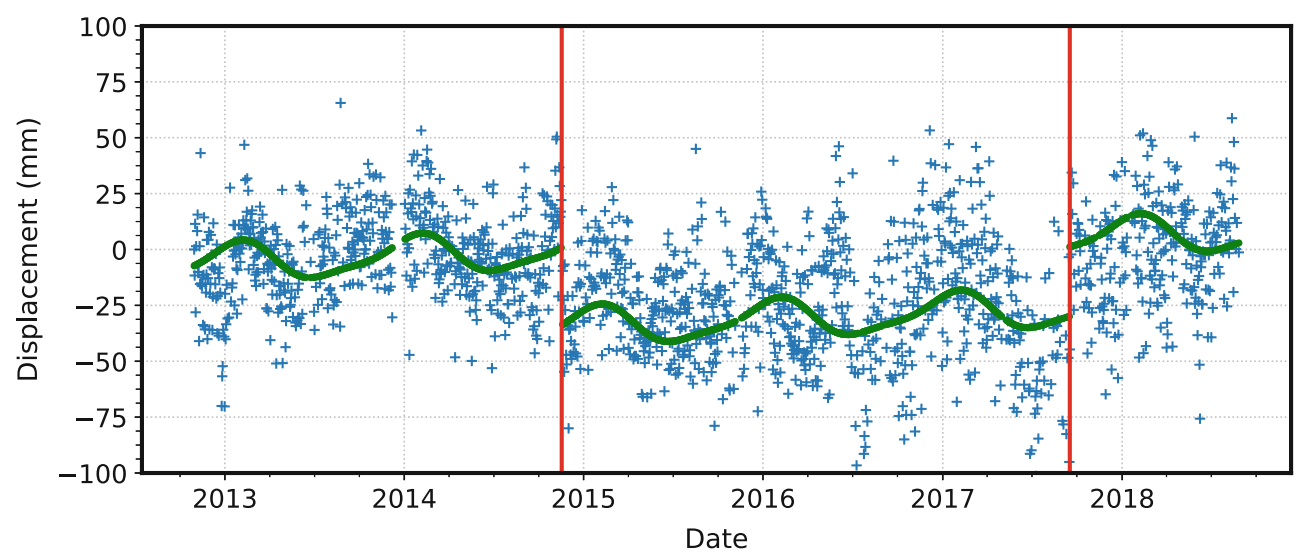

(a)

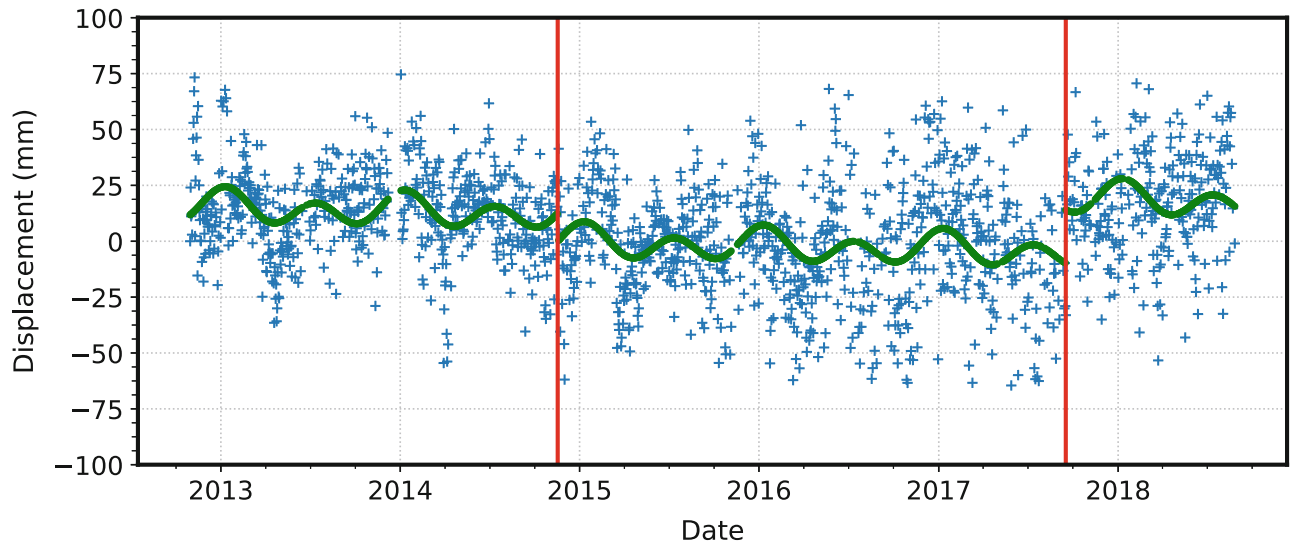

(b)

Fig. 8 Up component time series for the station TDB0, where an opposite velocity trend is visible. Blue dots represent the raw component determined by both software, and green dots the corresponding esti-

Table 3 Comparison of vertical velocities for LMMF and ABMF of this study with existing solutions

\begin{tabular}{l|l|l|l}
\hline $\mathrm{mm} / \mathrm{yr}$ & LMMF & ABMF & Solution end \\
\hline EPOS & $-2.40 \pm 0.46$ & $-0.84 \pm 0.40$ & Nov. 2018 \\
\hline GINS & $-2.41 \pm 0.41$ & $-0.39 \pm 0.42$ & Nov. 2018 \\
\hline ULR6a & $-3.55 \pm 0.48$ & N/A & Dec. 2014 \\
\hline NGL14 & $-2.70 \pm 1.33$ & $-2.37 \pm 1.15$ & Apr. 2019 \\
\hline JPL14 & $-2.49 \pm 0.54$ & $-1.74 \pm 0.88$ & Dec. 2019 \\
\hline ITRF14 & $-2.54 \pm 0.21$ & $-0.92 \pm 0.37$ & Dec. 2014 \\
\hline
\end{tabular}

subduction of the Tiburon ridge for the Saintes Islands (Leclerc and Feuillet 2019), and a potential deep interseismic loading for Martinique (Weil-Accardo et al. 2016).

We used only one software for velocity estimation since we mainly focussed on the GNSS processing itself, but some other velocity estimator software are available (e.g. Blewitt mated trend. Red vertical bars represent the discontinuities considered. (a) EPOS. (b) GINS

et al. 2016; Santamaría-Gómez 2019). The impact of the velocity estimation software on solutions have been analysed for instance by Mazzotti et al. (2020).

\section{Conclusion}

This work brings a comparison of the coordinate time series obtained for the same dataset with two different software but using consistent parameters. New homogeneously calculated vertical velocity fields are made available for geophysical modeling, with unprecedented density for the two Martinique and Guadeloupe Islands. A general subsidence trend is observed for both islands.

Acknowledgements We thank the different scientific institutes for the continuously operating GNSS acquisitions, the instrumental mainte- 
nance and for providing publicly and freely the observations. Data of the IPGP network, operated on site by the Guadeloupe and Martinique seismic and volcanologic observatories, are available on volobsis.ipgp. fr. Data of the IGN and the SONEL networks are available on rgp. ign.fr and sonel.org respectively. ORPHEON data were provided to the authors for a scientific use in the framework of the agreement between the GEODATA company (orpheon-network.fr) and the RESIF-RENAG network maintained by the CNRS-INSU (renag.resif.fr). We acknowledge the CNES (Centre national d'études spatiales) for its geodetic processing software GINS. We thank A. Walpersdorf \& an anonymous reviewer along with the editors J. Freymueller \& L. Sanchez, for their constructive comments which improved the content of this paper.

\section{References}

Altamimi Z, Rebischung P, Métivier L, Collilieux X (2016) ITRF2014: a new release of the international terrestrial reference frame modeling nonlinear station motions. J Geophys Res Solid Earth 121(8):6109-6131. https://doi.org/10.1002/2016JB013098. http:// doi.wiley.com/10.1002/2016JB013098

Ballu V, Bouin MN, Siméoni P, Crawford WC, Calmant S, Boré JM, Kanas T, Pelletier B (2011) Comparing the role of absolute sealevel rise and vertical tectonic motions in coastal flooding, Torres Islands (Vanuatu). Proc Nat Acad Sci 108(32):13019-13022. https:// doi.org/10.1073/pnas.1102842108. http://www.pnas.org/lookup/doi/ 10.1073/pnas.1102842108

Ballu V, Gravelle M, Wöppelmann G, de Viron O, Rebischung P, Becker M, Sakic P (2019) Vertical land motion in the Southwest and Central Pacific from available GNSS solutions and implications for relative sea levels. Geophys J Int 218(3):1537-1551. https://doi. org/10.1093/gii/ggz247. https://academic.oup.com/gji/article/218/3/ $1537 / 5499028$

Blewitt G, Kreemer C, Hammond WC, Gazeaux J (2016) MIDAS robust trend estimator for accurate GPS station velocities without step detection. J Geophys Res Solid Earth 121(3):20542068. https://doi.org/10.1002/2015JB012552. http://doi.wiley.com/ 10.1002/2015JB012552

Blewitt G, Hammond W, Kreemer C (2018) Harnessing the GPS data explosion for interdisciplinary science. Eos 99 . https://doi.org/10. 1029/2018EO104623. https://eos.org/project-updates/harnessingthe-gps-data-explosion-for-interdisciplinary-science

Bos MS, Fernandes RMS, Williams SDP, Bastos L (2013) Fast error analysis of continuous GNSS observations with missing data. J Geod 87(4):351-360. https://doi.org/10.1007/s00190-012-0605-0. http:// link.springer.com/10.1007/s00190-012-0605-0

Gendt G, Dick G, Söhne W (1998) GFZ analysis center of IGS-Annual Report. IGS 1996 Annual Report, pp 169-181

Heflin M, Moore A, Murphy D, Desai S, Bertiger W, Haines B, Kuang D, Sibthorpe A, Sibois A, Ries P, Hemberger D, Dietrich A (2019) Introduction to JPL's GPS time series GPS time series. https:// sideshow.jpl.nasa.gov/post/tables/GNSS_Time_Series.pdf

Leclerc F, Feuillet N (2019) Quaternary coral reef complexes as powerful markers of longterm subsidence related to deep processes at subduction zones: Insights from Les Saintes (Guadeloupe, French West Indies). Geosphere 15(4):983-1007. https://doi.org/10.1130/ GES02069.1

Léticée JL, Cornée JJ, Münch P, Fietzke J, Philippon M, Lebrun JF, De Min L, Randrianasolo A (2019) Decreasing uplift rates and
Pleistocene marine terraces settlement in the central lesser Antilles fore-arc (La Désirade Island, 16 deg. N). Quat Int 508(March):4359. https://doi.org/10.1016/j.quaint.2018.10.030. https://doi.org/10. 1016/j.quaint.2018.10.030

Loyer S, Perosanz F, Mercier F, Capdeville H, Marty JC (2012) Zerodifference GPS ambiguity resolution at CNES-CLS IGS Analysis Center. J Geod 86(11):991-1003. https://doi.org/10.1007/s00190012-0559-2. http://link.springer.com/10.1007/s00190-012-0559-2

Männel B, Brandt A, Bradke M, Sakic P, Brack A, Nischan T (2020) Status of IGS reprocessing activities at GFZ. In: International Association of Geodesy Symposia. Springer, Berlin. https://doi.org/10. 1007/1345_2020_98

Marty JC, Loyer S, Perosanz F, Mercier F, Bracher G, Legresy B, Portier L, Capdeville H, Fund F, Lemoine JM, Biancale R (2011) GINS: the CNES/GRGS GNSS scientific software. In: 3rd international colloquium scientific and fundamental aspects of the Galileo programme, ESA proceedings WPP326, vol 31, pp 8-10

Mazzotti S, Déprez A, Henrion E, Masson C, Masson F, Menut JL, Métois M, Nocquet JM, Rolland L, Sakic P, Socquet A, SantamariaGomez A, Valty P, Vergnolle M, Vernant P (2020) Comparative analysis of synthetic GNSS time series - bias and precision of velocity estimations. Research report, RESIF. https://hal.archivesouvertes.fr/hal-02460380

Mouslopoulou V, Oncken O, Hainzl S, Nicol A (2016) Uplift rate transients at subduction margins due to earthquake clustering. Tectonics 35(10):2370-2384. https://doi.org/10.1002/2016TC004248. http:// doi.wiley.com/10.1002/2016TC004248

Rabin M, Sue C, Walpersdorf A, Sakic P, Albaric J, Fores B (2018) Present-day deformations of the Jura Arc inferred by GPS surveying and earthquake focal mechanisms. Tectonics 37(10):37823804. https://doi.org/10.1029/2018TC005047. http://doi.wiley.com/ 10.1029/2018TC005047

Sakic P, Mansur G, Kitpracha C, Ballu V (2019) The GeodeZYX toolbox: a versatile Python 3 toolbox for geodetic-oriented purposes. https://doi.org/10.5880/GFZ.1.1.2019.002. http://dataservices.gfzpotsdam.de/panmetaworks/showshort.php?id=escidoc: 4754924

Santamaría-Gómez A (2019) SARI: interactive GNSS position time series analysis software. GPS Solutions 23(2):1-6. https://doi. org/10.1007/s10291-019-0846-y. http://dx.doi.org/10.1007/s10291019-0846-y

Santamaría-Gómez A, Gravelle M, Dangendorf S, Marcos M, Spada G, Wöppelmann G (2017) Uncertainty of the 20th century sea-level rise due to vertical land motion errors. Earth Planet Sci Lett 473:2432. https://doi.org/10.1016/j.eps1.2017.05.038. http://dx.doi.org/10. 1016/j.eps1.2017.05.038

Symithe S, Calais E, de Chabalier JB, Robertson R, Higgins M (2015) Current block motions and strain accumulation on active faults in the Caribbean. J Geophys Res Solid Earth 120(5):37483774. https://doi.org/10.1002/2014JB011779. http://doi.wiley.com/ 10.1002/2014JB011779

Uhlemann M, Gendt G, Ramatschi M, Deng Z (2015) GFZ global multi-GNSS network and data processing results. In: International association of geodesy symposia, vol 12. Springer, New York, pp 673-679. https://doi.org/10.1007/1345_2015_120

Walpersdorf A, Pinget L, Vernant P, Sue C, Deprez A (2018) Does long-term GPS in the Western Alps finally confirm earthquake mechanisms? Tectonics 37(10):3721-3737. https://doi.org/10.1029/ 2018TC005054. http://doi.wiley.com/10.1029/2018TC005054

Weil-Accardo J, Feuillet N, Jacques E, Deschamps P, Beauducel F, Cabioch G, Tapponnier P, Saurel JM, Galetzka J (2016) Two hun- 
dred thirty years of relative sea level changes due to climate and megathrust tectonics recorded in coral microatolls of Martinique (French West Indies). J Geophys Res Solid Earth 121(4):28732903. https://doi.org/10.1002/2015JB012406. http://doi.wiley.com/ 10.1002/2015JB012406
Wöppelmann G, Testut L, Créach R (2011) La montée du niveau des océans par marégraphie et géodésie spatiale: contributions françaises à une problématique mondiale. Annales Hydrographiques Gème Série 8(777):11-14

Open Access This chapter is licensed under the terms of the Creative Commons Attribution 4.0 International License (http://creativecommons. org/licenses/by/4.0/), which permits use, sharing, adaptation, distribution and reproduction in any medium or format, as long as you give appropriate credit to the original author(s) and the source, provide a link to the Creative Commons licence and indicate if changes were made.

The images or other third party material in this chapter are included in the chapter's Creative Commons licence, unless indicated otherwise in a credit line to the material. If material is not included in the chapter's Creative Commons licence and your intended use is not permitted by statutory regulation or exceeds the permitted use, you will need to obtain permission directly from the copyright holder. 